\title{
Índice produtivo e qualidade de ovos de galinhas poedeiras submetidas a diferentes métodos de debicagem
}

\author{
Javer Alves Vieira Filho(1), Edivaldo Antônio Garcia(1), Eunice Oba ${ }^{(2)}$, Tiago Antônio dos Santos(1), \\ Anderson Pontes Silva ${ }^{(3)}$, Andréa Britto Molino ${ }^{(4)}$, Ibiara Correia de Lima Almeida Paz ${ }^{(1)}$ \\ e Grace Alessandra de Araújo Baldo(1)
}

\begin{abstract}
(1)Universidade Estadual Paulista, Faculdade de Medicina Veterinária e Zootecnia, Departamento de Produção Animal, Fazenda Experimental Lageado, CEP 18618-000 Botucatu, SP, Brasil. E-mail: javeralves@yahoo.com.br, egarcia@fmvz.unesp.br, tiagoant.santos@gmail.com, ibiarapaz@fmvz.unesp.br, graaraujo20@hotmail.com (2)Universidade Estadual Paulista, Faculdade de Medicina Veterinária e Zootecnia, Departamento de Reprodução Animal e Radiologia Veterinária, Distrito de Rubião Júnior, CEP 18618-970 Botucatu, SP, Brasil. E-mail: euniceoba@fmvz.unesp.br (3)Lohmann do Brasil, CEP 15020-360 São José do Rio Preto, SP, Brasil. E-mail: asilva@ltz.com.br (4)Universidade de São Paulo, Faculdade de Medicina Veterinária e Zootecnia, Departamento de Nutrição e Produção Animal, Avenida Duque de Caxias Norte, no 225, CEP 13635-900, Pirassununga, SP, Brasil. E-mail: molinoab@fmvz.unesp.br
\end{abstract}

Resumo - O objetivo deste trabalho foi avaliar o efeito da debicagem, por meio de lâmina quente ou por radiação infravermelha, sobre os indicadores produtivos e de qualidade de ovos, em três linhagens de galinhas poedeiras na primeira semana de vida, e se uma segunda debicagem seria necessária na décima semana de idade. As aves foram distribuídas em um delineamento inteiramente ao acaso, em arranjo fatorial $2 \times 3 \times 2$ (primeira debicagem por meio de radiação infravermelha ou por lâmina quente $\mathrm{x}$ linhagens Lohmann LSL, Hy-line W-36 e Lohmann Brown x com ou sem debicagem à décima semana de idade), no total de doze tratamentos, com seis repetições. A debicagem por radiação infravermelha, na primeira semana de vida, proporciona os mesmos resultados produtivos e de qualidade dos ovos que o método convencional por lâmina quente. Não houve mortes por canibalismo em aves das três linhagens que não foram submetidas à segunda debicagem, mas se observou decréscimo de $8 \%$ da viabilidade, em aves à $63 .^{a}$ semana de idade.

Termos para indexação: bem-estar, produção de ovos, radiação infravermelha, tratamento de bico.

\section{Production index and quality of eggs of laying hens subjected to different methods of beak trimming}

\begin{abstract}
The objective of this work was to evaluate the effect of beak trimming, by hot blade or infrared radiation, on the production indicators and egg quality of three laying hen strains in the first week of life, and whether a second beak trimming would be necessary in the tenth week. Birds were distributed in a completely randomized design with $2 \times 3 \times 2$ factorial arrangement (first beak trimming by means of infrared radiation or hot blade $\mathrm{x}$ the strains Lohmann LSL, Hy-line W-36, and Lohmann Brown $\mathrm{x}$ with or without beak trimming at the tenth week of age), totaling twelve treatments with six replicates. Beak trimming by infrared radiation, in the first week of life, provides the same production results and egg quality as the conventional method by hot blade. There were no deaths from cannibalism for birds of the three strains that were not subjected to the second beak trimming; however, a decrease of $8 \%$ viability was observed in birds at the $63^{\text {th }}$ week of age.
\end{abstract}

Index terms: welfare, egg production, infrared radiation, beak treatment.

\section{Introdução}

O mercado consumidor preocupa-se cada vez mais com a qualidade do produto final, exigindo informações sobre as metodologias adotadas durante a produção e optando por produtos que estejam em conformidade com as boas práticas de manejo e bem-estar animal. No atual molde de produção, a alta densidade de alojamento e a debicagem são os pontos mais contestados quanto ao bem-estar animal. A forte pressão feita pelo mercado consumidor mostra que algumas práticas adotadas pela avicultura devem ser revisadas, para atender a esta preocupação (Marchant-Forde \& Cheng, 2010).

A debicagem é uma técnica de manejo que visa reduzir os efeitos deletérios das altas densidades de alojamento. Geralmente, é utilizada em plantéis de postura comercial, matrizes de frangos de corte, patos 
e perus (Fournier et al., 2015). Esta prática tem o objetivo de evitar lesões oriundas das bicadas de penas e canibalismo e, indiretamente, garantir consumo uniforme de alimento (Cunningham \& Mauldin, 1996; Gentle, 2011). Além disto, aves submetidas à debicagem apresentam comportamento menos agressivo, melhoria da taxa de postura e redução dos ovos bicados e de mortalidade (Laganá et al., 2011).

Embora seja uma prática benéfica do ponto de vista produtivo, a debicagem submete as aves a estresse pois se manipulam todas as aves do lote - e demanda cuidados no que diz respeito ao comprimento do bico, temperatura da lâmina e, principalmente, treinamento da equipe que realizará a operação (Fahey et al., 2007). Todos estes aspectos são determinantes para o sucesso produtivo do lote.

Metodologias menos invasivas vêm sendo desenvolvidas, como o tratamento de bico realizado por meio de radiação infravermelha, que mostra benefícios como a ausência de sangramento e, consequentemente, menor risco de contaminação por microrganismos. Este método não realiza o corte e, sim, expõe o tecido córneo do bico a um feixe de radiação infravermelha, que leva à queda gradual da região exposta em até 14 dias após a realização do tratamento.

Ao se comparar a debicagem com lâmina quente ao tratamento por radiação infravermelha, em aves da linhagem Bovans White, constatou-se que o método alternativo de debicagem proporcionou redução da agressividade e melhores condições de empenamento (Dennis \& Cheng, 2010). As aves tratadas pelo método de radiação infravermelha gastaram menos tempo se alimentando e apresentaram maior massa corporal, em comparação às aves debicadas por lâmina quente. Este resultado é reflexo de melhor eficiência alimentar, em animais tratados pelo método alternativo de debicagem.

Assim, esforços vêm sendo direcionados para o desenvolvimento de novas técnicas que atendam às necessidades do mercado consumidor e mantenham os atuais padrões produtivos da avicultura industrial.

O objetivo deste trabalho foi avaliar o efeito da debicagem por lâmina quente ou por radiação infravermelha, sobre os indicadores produtivos $\mathrm{e}$ de qualidade de ovos em três linhagens de galinhas poedeiras, na primeira semana de vida, e verificar a necessidade de uma segunda debicagem na décima semana de idade.

\section{Material e Métodos}

O experimento foi realizado na Universidade Estadual Paulista Júlio de Mesquita Filho - Unesp, Campus Botucatu, SP, Faculdade de Medicina Veterinária e Zootecnia, Setor de Avicultura, e compreendeu da primeira semana de vida até a fase de produção de poedeiras comerciais, da $18 .^{\mathrm{a}}$ à 63 . $^{\mathrm{a}}$ semana de idade. Utilizaram-se 672 galinhas poedeiras de três linhagens comerciais Lohmann LSL (240 aves), Hy-line W-36 (240 aves) e Lohmann Brown (192 aves), alojadas em aviário tipo californiano, equipado com gaiolas metálicas nas dimensões $100 \times 45 \times 45 \mathrm{~cm}$, com densidade de alojamento de $450 \mathrm{~cm}^{2}$ por ave para as linhagens Lohmann LSL e Hy-line W-36, e de $562,5 \mathrm{~cm}^{2}$ por ave para a linhagem Lohmann Brown. Todas as gaiolas continham comedouros individuais e bebedouros do tipo nipple. Durante o período experimental, as aves receberam dietas iguais, bem como programa de iluminação. A alimentação e a água foram fornecidas ad libitum, e o arraçoamento foi realizado duas vezes ao dia.

As aves foram distribuídas em um delineamento inteiramente ao acaso, em arranjo fatorial $2 \times 3 \times 2$ (primeira debicagem por meio de radiação infravermelha ou por lâmina quente $\mathrm{x}$ linhagens Lohmann LSL, Hy-line W-36 e Lohmann Brown x com ou sem debicagem à décima semana de idade), perfazendo doze tratamentos, com seis repetições cada. Nos tratamentos constituídos pelas linhagens Lohmman LSL e Hy-line W-36, utilizaram-se 10 aves por parcela experimental; nos tratamentos constituídos pela linhagem Lohmman Brown, utilizaram-se 8 aves por parcela experimental. Esta diferença do número de aves se deve às diferentes densidades de alojamento exigidas para linhagens de poedeiras leves e semipesadas.

A debicagem por radiação infravermelha foi realizada ao primeiro dia de vida, ainda no incubatório, com o equipamento poultry service processor (PSP), desenvolvido pela empresa Nova-Tech Engenharia, seguindo as seguintes especificações: tratamento de bico a $2 \mathrm{~mm}$ da narina, por intensidade de luz de $52 \mathrm{~nm}$ e espelho como material de reflexão. No método convencional de debicagem com lâmina quente seguiram-se as seguintes diretrizes: corte e cauterização a $4 \mathrm{~mm}$ da narina, aos sete dias de vida.

$\mathrm{Na}$ décima semana de idade das aves, realizouse a segunda debicagem, pelas diretrizes: corte e 
cauterização do bico a $7 \mathrm{~mm}$ da narina. As duas debicagens realizadas por lâmina quente foram feitas com um debicador Lyon $50 / 60 \mathrm{~Hz}$ e 70-210 W, com a lâmina mantida em torno de $700^{\circ} \mathrm{C}$.

Os indicadores de desempenho avaliados foram: maturidade sexual, expressa em dias necessários para as aves atingirem $50 \%$ de postura; consumo de ração, obtido semanalmente, por meio da relação entre a quantidade de alimento consumido em cada parcela, em razão do número médio de aves, expresso em gramas por ave por dia; percentagem de postura, que é a relação entre o número de ovos produzidos, em função do número médio de aves por parcela, expresso em percentagem de postura por ave por dia; massa média dos ovos, obtida pela pesagem de todos os ovos produzidos, com o valor médio expresso em gramas; ovos por ave presente, quantificado pelo número de ovos produzidos durante as semanas experimentais; massa de ovos, obtida pela multiplicação da percentagem média de postura pela massa média dos ovos; conversão alimentar - expressa em $\mathrm{kg}$ de ração por $\mathrm{kg}$ de ovos e $\mathrm{kg}$ de ração por dúzia de ovos -, representada pela relação entre o consumo de alimento e a massa de ovos, e por dúzias de ovos produzidos; canibalismo, representado pelas mortes decorrentes de canibalismo, expresso em percentagem; e viabilidade, obtida de registros diários das mortes em cada parcela e expressas em percentagem ao final da 63. ${ }^{\mathrm{a}}$ semana. Às 18 . $^{\mathrm{a}}$ e 63 . $^{\mathrm{a}}$ semanas, foram medidos os seguintes parâmetros: comprimento de bico, por meio de paquímetro digital com precisão de $0,01 \mathrm{~mm}$; e a massa corporal, pela pesagem de todas as aves de duas repetições por tratamento.

Para avaliação das características de qualidade interna e externa dos ovos, o experimento foi dividido em seis períodos de 28 dias, de forma que, ao final de cada período, dois ovos íntegros, de duas repetições por tratamento, foram coletados durante três dias consecutivos para a obtenção dos indicadores de qualidade.

Os indicadores avaliados foram: gravidade específica, obtida após a imersão dos ovos em solução salina de 1,060 a 1,100 $\mathrm{g} \mathrm{cm}^{-3}$ (Moreng \& Avens, 1990); resistência da casca à quebra, avaliada com o auxílio de um aparelho texturômetro TA.XT plus - Texture Analyser, equipado com sonda de $75 \mathrm{~mm}$ $(\mathrm{p} / 2)$ e velocidade do teste de $1 \mathrm{~mm} \mathrm{~s}^{-1}$; espessura de casca, representada pela média de três medições realizadas na região equatorial da casca, com $\mathrm{o}$ auxílio de um paquímetro digital; percentagem de gema, albúmen e casca, calculada pela relação entre a massa dos respectivos constituintes e a massa do ovo; unidade Haugh, determinada a partir dos dados de massa dos ovos e altura do albúmen, pela fórmula proposta por Card \& Nesheim (1968): $\mathrm{UH}=100 \log \left(\mathrm{H}+7,57-1,7 \mathrm{~W}^{0,37}\right)$, em que H é a altura do albúmen $(\mathrm{mm})$ e $\mathrm{W}$ é a massa do ovo $(\mathrm{g})$.

Os dados foram submetidos à análise de variância, pelo programa SAS 9.2, com as médias comparadas pelo teste de Tukey, a 5\% de probabilidade. As variáveis que não apresentaram distribuição normal foram transformadas pela correção $\log 10$ para análise.

\section{Resultados e Discussão}

Durante todo o período experimental, não se observou canibalismo entre as aves.

Houve interação entre os fatores linhagem e debicagem na recria e, ainda, entre debicagem na cria e debicagem na recria, quanto ao comprimento de bico (Tabela 1).

Para o fator linhagem, houve diferença significativa em todas as características. É possível constatar que as aves das linhagens Lohmann LSL e Lohmann Brown mostraram maior massa inicial e consumo de ração, porém, a pior conversão alimentar por massa de ovos, em comparação às aves da linhagem Hy-line W-36. Quanto à conversão alimentar por dúzia e massa final, as aves das linhagens Lohmann LSL e Hy-line W-36 mostraram melhor conversão e menor massa corporal à 63. ${ }^{a}$ semana do que as aves da linhagem Lohmann Brown.

Para o fator debicagem na cria, constatou-se efeito $(\mathrm{p}<0,05)$ apenas sobre a característica massa inicial, em que as aves submetidas ao tratamento de bico por meio de lâmina quente foram mais leves, no início da fase de produção, comparativamente às que tiveram o tratamento de bico por meio de radiação infravermelha. Dennis et al. (2009) também verificaram que não houve diferença entre a massa corporal à $30 .^{a}$ semana, em poedeiras debicadas por lâmina quente ou por radiação infravermelha.

Ao se comparar o tratamento de bico por radiação infravermelha ao método por lâmina quente, notase que a metodologia alternativa exige menor tempo para recuperação e retorno mais rápido ao consumo 
normal de alimento (Marchant-Forde \& Cheng, 2010). $\mathrm{O}$ tratamento de bico por radiação infravermelha também proporcionou os mesmos resultados produtivos esperados para o tratamento por lâmina quente, e é uma alternativa viável para a realização da primeira debicagem em poedeiras comerciais, segundo Dennis et al. (2009).

Considerando-se o fator debicagem na recria, é possível observar que aves submetidas à segunda debicagem são mais leves, tanto ao início quanto ao final do período produtivo, e com bicos menores do que as aves que não foram submetidas à segunda debicagem (Tabela 1). O resultado de menor massa corporal, ao início do período produtivo, é reflexo da redução de consumo de alimento nos dias que se seguiram ao processo de debicagem (Lee \& Craig, 1990; Cunningham \& Mauldin, 1996; Glatz, 2003). O aumento da sensibilidade após a debicagem ocorre em consequência do dano causado aos mecanorreceptores do bico, que fizeram com que a aves ficassem apáticas e apresentassem uma redução do comportamento de ingestão de alimentos (Fahey et al., 2007).

As demais características não foram alteradas pela aplicação ou não da segunda debicagem à décima semana de idade, à exceção do comprimento de bico (Tabelas 1 e 2). É possível constatar que a não realização da segunda debicagem exerce poucos efeitos negativos sobre o desempenho produtivo de poedeiras comerciais, pois não se observou frequência de canibalismo entre as aves e apenas a massa corporal e o comprimento de bico foram alterados pela aplicação da debicagem à décima semana de vida. Observa-se que as linhagens modernas estão menos suscetíveis ao canibalismo e à bicagem de penas (Janczak \& Riber, 2015) e são consideradas mais dóceis e adaptadas ao sistema de produção em gaiolas.

As linhagens diferiram quanto ao crescimento do bico, e as aves da linhagem Lohmann LSL apresentaram bicos maiores do que as demais linhagens testadas (Tabela 2). A aplicação da segunda debicagem atua não só na prevenção do canibalismo, mas também como forma de padronizar o tamanho do bico e reduzir seu potencial agressivo.

As aves tratadas por meio de radiação infravermelha apresentaram menor crescimento do bico do que as aves debicadas por lâmina quente (Tabela 2). Marchant-Forde \& Cheng (2010) afirmam que o tratamento de bico por meio de radiação infravermelha é mais efetivo em inibir o crescimento do bico do que a debicagem por lâmina quente. As poedeiras da linhagem Lohmann, quando submetidas à debicagem por radiação infravermelha, também mostraram

Tabela 1. Consumo de alimento e condição corporal de poedeiras de três linhagens comerciais, submetidas a diferentes protocolos de debicagem na cria na $1 .^{\text {a }}$ semana de idade e na recria na $10 .^{\mathrm{a}}$ semana de idade ${ }^{(1)}$.

\begin{tabular}{|c|c|c|c|c|c|c|c|}
\hline Tratamento & $\begin{array}{l}\text { Número } \\
\text { de aves }\end{array}$ & $\begin{array}{c}\text { Massa inicial } \\
(\mathrm{kg})\end{array}$ & $\begin{array}{l}\text { CR (g por ave } \\
\text { por dia) }\end{array}$ & $\begin{array}{c}\text { CA por massa } \\
\text { de ovos }\left(\mathrm{kg} \mathrm{kg}^{-1}\right)\end{array}$ & $\begin{array}{l}\text { CA por dúzia (kg } \\
\text { por dúzia) }\end{array}$ & $\begin{array}{l}\text { Massa final } \\
(\mathrm{kg})\end{array}$ & $\begin{array}{l}\text { Comprimento de } \\
\text { bico }(\mathrm{mm})\end{array}$ \\
\hline \multicolumn{8}{|l|}{ Linhagens (L) } \\
\hline Lohmann LSL & 240 & $1,215 \mathrm{~B}$ & $113,05 \mathrm{~A}$ & $2,08 \mathrm{~A}$ & $1,53 \mathrm{AB}$ & $1,662 \mathrm{~B}$ & $11,70 \mathrm{~A}$ \\
\hline Hy-line W-36 & 240 & $1,189 \mathrm{C}$ & $104,12 \mathrm{~B}$ & $2,00 \mathrm{~B}$ & $1,46 \mathrm{~B}$ & $1,643 \mathrm{~B}$ & $11,32 \mathrm{~B}$ \\
\hline Lohmann Brown & 192 & $1,429 \mathrm{~A}$ & $116,56 \mathrm{~A}$ & $2,06 \mathrm{~A}$ & $1,60 \mathrm{~A}$ & $1,925 \mathrm{~A}$ & $11,49 \mathrm{AB}$ \\
\hline \multicolumn{8}{|l|}{ Debicagem na cria (D) } \\
\hline Infravermelho & 336 & $1,287 \mathrm{~A}$ & $111,18 \mathrm{~A}$ & $2,05 \mathrm{~A}$ & $1,53 \mathrm{~A}$ & $1,747 \mathrm{~A}$ & $11,46 \mathrm{~A}$ \\
\hline Lâmina Quente & 336 & $1,267 \mathrm{~B}$ & $111,30 \mathrm{~A}$ & $2,04 \mathrm{~A}$ & $1,53 \mathrm{~A}$ & $1,740 \mathrm{~A}$ & $11,54 \mathrm{~A}$ \\
\hline \multicolumn{8}{|l|}{ Debicagem na recria $(\mathrm{R})$} \\
\hline Com debicagem & 336 & $1,259 \mathrm{~B}$ & $111,06 \mathrm{~A}$ & $2,05 \mathrm{~A}$ & $1,52 \mathrm{~A}$ & $1,726 \mathrm{~B}$ & $11,08 \mathrm{~B}$ \\
\hline Sem debicagem & 336 & $1,296 \mathrm{~A}$ & $111,42 \mathrm{~A}$ & $2,04 \mathrm{~A}$ & $1,54 \mathrm{~A}$ & $1,761 \mathrm{~A}$ & $11,92 \mathrm{~A}$ \\
\hline Coeficiente de variação (\%) & & 9,07 & 5,86 & 5,34 & 6,20 & 7,96 & 4,68 \\
\hline Linhagens (L) & & $<0,05$ & $<0,05$ & $<0,05$ & $<0,05$ & $<0,05$ & $<0,05$ \\
\hline Debicagem na cria (D) & & $<0,05$ & 0,89 & 0,84 & 0,73 & 0,63 & 0,31 \\
\hline Debicagem na recria $(\mathrm{R})$ & & $<0,05$ & 0,69 & 0,44 & 0,37 & $<0,05$ & $<0,05$ \\
\hline $\mathrm{L} \times \mathrm{D}$ & & 0,91 & 0,27 & 0,19 & 0,28 & 0,86 & 0,86 \\
\hline $\mathrm{L} \times \mathrm{R}$ & & 0,32 & 0,16 & 0,72 & 0,37 & 0,09 & $<0,05$ \\
\hline $\mathrm{D} \times \mathrm{R}$ & & 0,22 & 0,06 & 0,31 & 0,79 & 0,19 & $<0,05$ \\
\hline $\mathrm{L} \times \mathrm{D} \times \mathrm{R}$ & & 0,48 & 0,31 & 0,68 & 0,85 & 0,72 & 0,26 \\
\hline
\end{tabular}

${ }^{(1)}$ Médias seguidas por letras iguais, nas colunas, não diferem pelo teste de Tukey, a $5 \%$ de probabilidade. CR, consumo de ração; CA, conversão alimentar. 
comprimentos menores de bico do que aquelas que foram debicadas por meio de lâmina quente (Carruthers et al., 2012).

Com relação à maturidade sexual, nota-se que as aves da linhagem Lohmann Brown são mais precoces, ou seja, atingem $50 \%$ de postura quatro dias antes do que as demais linhagens testadas (Tabela 3 ). Este resultado pode ser reflexo da maior massa corporal ao início do período produtivo. Para as demais características,

Tabela 2. Desdobramento das interações debicagem na recria na $10 .^{a}$ semana de idade e linhagens (LxR), e debicagem na cria na $1 .^{\mathrm{a}}$ semana de idade e na recria (DxR), quanto ao comprimento de bico ${ }^{(1)}$.

\begin{tabular}{|c|c|c|c|}
\hline \multirow[t]{2}{*}{ Tratamento } & \multicolumn{2}{|c|}{ Comprimento de bico (mm) } & \multirow[t]{2}{*}{ Média } \\
\hline & Com & Sem & \\
\hline Linhagen (L) & \multicolumn{2}{|c|}{ Debicagem na recria $(\mathrm{R})$} & \\
\hline Lohmann LSL (240 aves) & $11,10 \mathrm{Ab}$ & $12,30 \mathrm{Aa}$ & 11,70 \\
\hline Hy-line W-36 (240 aves) & $11,05 \mathrm{Ab}$ & $11,58 \mathrm{Ba}$ & 11,32 \\
\hline Lohmann Brown (192 aves) & $11,09 \mathrm{Ab}$ & $11,89 \mathrm{Ba}$ & 11,49 \\
\hline \multicolumn{4}{|l|}{ Debicagem na cria (D) } \\
\hline Infravermelha (336 aves) & $10,92 \mathrm{Ab}$ & $12,00 \mathrm{Aa}$ & 11,46 \\
\hline Lâmina quente (336 aves) & $11,24 \mathrm{Bb}$ & $11,85 \mathrm{Aa}$ & 11,54 \\
\hline Média & 11,08 & 11,92 & \\
\hline
\end{tabular}

${ }^{(1)}$ Médias seguidas por letras iguais, maiúsculas nas colunas e minúsculas nas linhas, não diferem pelo teste de Tukey, a 5\% de probabilidade. nota-se que as aves das linhagens Lohmann LSL e Lohmann Brown apresentaram maior percentagem de postura, mais ovos por ave presente e massa de ovos, em comparação às aves da linhagem Hy-line W-36.

Contrariamente ao observado no atual ensaio, Angevaare et al. (2012) constataram que aves debicadas por meio de radiação infravermelha apresentaram um ligeiro atraso de maturidade sexual. De acordo com os autores, este pequeno atraso pode ser benéfico, uma vez que permite o completo desenvolvimento corporal e a mineralização do esqueleto.

Pelos resultados aqui obtidos, pode-se admitir a adoção de apenas uma debicagem durante a fase de cria, realizada por lâmina quente ou radiação infravermelha e, ainda, que a ausência da segunda debicagem não implicou em aumento na incidência de canibalismo, porém teve um efeito negativo sobre a viabilidade, de forma que aves não debicadas à décima semana tiveram redução de $8 \%$ de viabilidade à 63 . $^{a}$ semana de idade.

Apesar da constatação de que apenas uma debicagem, realizada no período de cria, foi suficiente para evitar a incidência de canibalismo, a abolição por completo da técnica de debicagem deve ser analisada com critério, já que isso pode implicar aumento dos índices de mortalidade, em outras condições, como

Tabela 3. Indicadores de produtividade de três linhagens de poedeiras comerciais, submetidas a diferentes protocolos de debicagem na cria na $1 .^{\mathrm{a}}$ semana de idade e na recria na $10{ }^{\mathrm{a}}$ semana de idade ${ }^{(1)}$.

\begin{tabular}{|c|c|c|c|c|c|c|c|c|c|c|}
\hline Tratamento & $\begin{array}{c}\text { Número de } \\
\text { aves }\end{array}$ & $\begin{array}{c}\text { MS } \\
\text { (dias) }\end{array}$ & $\begin{array}{l}\text { PP } \\
(\%)\end{array}$ & $\begin{array}{c}\mathrm{MM} \\
(\mathrm{g})\end{array}$ & $\mathrm{OA}$ & $\begin{array}{l}\mathrm{MO} \\
(\mathrm{g})\end{array}$ & $\begin{array}{c}\text { Viabilidade } \\
(\%)\end{array}$ & $\begin{array}{c}\text { Gema } \\
(\%)\end{array}$ & $\begin{array}{c}\text { Albúmen } \\
(\%)\end{array}$ & $\begin{array}{c}\text { Unidade } \\
\text { Haugh }\end{array}$ \\
\hline \multicolumn{11}{|l|}{ Linhagens } \\
\hline Lohmann LSL & 240 & $136 \mathrm{~A}$ & $86,48 \mathrm{~A}$ & $60,22 \mathrm{AB}$ & $271 \mathrm{~A}$ & $56,01 \mathrm{~A}$ & $91,84 \mathrm{~A}$ & $25,18 \mathrm{~A}$ & $65,42 \mathrm{~A}$ & $89,84 \mathrm{~A}$ \\
\hline Hy-line W-36 & 240 & $136 \mathrm{~A}$ & $84,49 \mathrm{~B}$ & $59,06 \mathrm{~B}$ & $269 \mathrm{~A}$ & $53,51 \mathrm{~B}$ & $88,09 \mathrm{~A}$ & $25,46 \mathrm{~A}$ & $65,11 \mathrm{~A}$ & $88,89 \mathrm{~A}$ \\
\hline Lohmann Brown & 192 & $132 \mathrm{~B}$ & $86,60 \mathrm{~A}$ & $61,35 \mathrm{~A}$ & $272 \mathrm{~A}$ & $56,73 \mathrm{~A}$ & $89,68 \mathrm{~A}$ & $25,03 \mathrm{~A}$ & $65,62 \mathrm{~A}$ & $87,86 \mathrm{~A}$ \\
\hline \multicolumn{11}{|l|}{ Debicagem na cria } \\
\hline Infravermelho & 336 & $135 \mathrm{~A}$ & $85,74 \mathrm{~A}$ & $60,22 \mathrm{~A}$ & $271 \mathrm{~A}$ & $55,30 \mathrm{~A}$ & $89,56 \mathrm{~A}$ & $25,15 \mathrm{~A}$ & $65,44 \mathrm{~A}$ & $88,75 \mathrm{~A}$ \\
\hline Lâmina quente & 336 & $135 \mathrm{~A}$ & $86,11 \mathrm{~A}$ & $60,20 \mathrm{~A}$ & $271 \mathrm{~A}$ & $55,54 \mathrm{~A}$ & $90,16 \mathrm{~A}$ & $25,30 \mathrm{~A}$ & $65,32 \mathrm{~A}$ & $88,98 \mathrm{~A}$ \\
\hline \multicolumn{11}{|l|}{ Debicagem na recria } \\
\hline Com & 336 & $135 \mathrm{~A}$ & $86,04 \mathrm{~A}$ & $60,08 \mathrm{~A}$ & $271 \mathrm{~A}$ & $55,34 \mathrm{~A}$ & $93,63 \mathrm{~A}$ & $25,22 \mathrm{~A}$ & $65,39 \mathrm{~A}$ & $88,96 \mathrm{~A}$ \\
\hline Sem & 336 & $135 \mathrm{~A}$ & $85,80 \mathrm{~A}$ & $60,34 \mathrm{~A}$ & $270 \mathrm{~A}$ & $55,5 \mathrm{~A}$ & $86,11 \mathrm{~B}$ & $25,56 \mathrm{~A}$ & $65,38 \mathrm{~A}$ & $88,77 \mathrm{~A}$ \\
\hline Coeficiente de variação (\%) & & 2,04 & 3,52 & 2,29 & 3,52 & 4,11 & 9,49 & 4,52 & 1,74 & 4,00 \\
\hline$\overline{\text { Linhagens (L) }}$ & & $<0,05$ & $<0,05$ & $<0,05$ & 0,5 & $<0,05$ & 0,7 & 0,42 & 0,3 & 0,17 \\
\hline Debicagem na cria (D) & & 0,45 & 0,59 & 0,92 & 0,99 & 0,59 & 0,87 & 0,58 & 0,64 & 0,79 \\
\hline Debicagem na recria $(\mathrm{R})$ & & 0,33 & 0,73 & 0,3 & 0,93 & 0,72 & $<0,05$ & 0,99 & 0,96 & 0,82 \\
\hline $\mathrm{L} \times \mathrm{D}$ & & $<0,05$ & 0,19 & 0,2 & 0,35 & 0,72 & 0,88 & 0,52 & 0,49 & 0,67 \\
\hline $\mathrm{L} \times \mathrm{R}$ & & 0,89 & 0,48 & 0,75 & 0,85 & 0,52 & 0,99 & 0,49 & 0,3 & 0,68 \\
\hline $\mathrm{D} \times \mathrm{R}$ & & 0,09 & 0,36 & 0,86 & 0,38 & 0,33 & 0,39 & 0,47 & 0,65 & 0,80 \\
\hline $\mathrm{L} \times \mathrm{D} \times \mathrm{R}$ & & 0,94 & 0,58 & 0,32 & 0,71 & 0,24 & 0,35 & 0,20 & 0,37 & 0,32 \\
\hline
\end{tabular}

${ }^{(1)}$ Médias seguidas por letras iguais, nas colunas, não diferem pelo teste de Tukey, a $5 \%$ de probabilidade. MS, maturidade sexual; PP, percentagem de postura (\% postura por dia); MM, massa média dos ovos; OA, ovos por ave presente; MO, massa de ovos. 
o ocorrido com aves que não foram submetidas à debicagem e que apresentaram aumento de $40 \%$ de mortes por canibalismo, em comparação às aves que foram submetidas a apenas uma debicagem, aos nove dias de vida (Guesdon et al., 2006).

Observa-se que a linhagem semipesada (Lohmann Brown) é mais precoce e atinge $50 \%$ de postura de ovos antes das outras duas linhagens testadas, independentemente da metodologia de debicagem adotada na fase de cria (Tabela 4). Este resultado se deve ao fato de que as aves desta linhagem apresentam maior massa corporal e, consequentemente, desenvolvimento mais rápido dos sistemas ósseo e reprodutivo, responsáveis por sustentar a produção de ovos.

A utilização da radiação infravermelha, para debicagem das aves da linhagem Lohmann LSL, implica redução de até dois dias para que estas atinjam a maturidade sexual. As aves da linhagem Hy-line W-36 são mais tardias, e a utilização da debicagem por lâmina quente ou radiação infravermelha não implica variação quanto à maturidade sexual (Tabela 4).

Não se observou efeito significativo de nenhum dos fatores sobre a qualidade interna dos ovos, quanto à debicagem na cria e na recria (Tabela 3). Assim, as linhagens, mesmo diferentes geneticamente, apresentaram padrões semelhantes quanto à qualidade interna dos ovos produzidos. Laganá et al. (2011) também constataram que a debicagem de um terço do bico de codornas japonesas exerce pouco efeito sobre a qualidade interna e de casca dos ovos.

Não houve influência dos fatores avaliados sobre os indicadores de qualidade de casca dos ovos (Tabela 5). Mertens et al. (2009) também observaram que poedeiras comerciais, debicadas ou não à sexta semana de idade, também apresentaram valores semelhantes de massa de ovos, espessura de casca e unidade Haugh, no período da $27 .{ }^{\mathrm{a}}$ à $60{ }^{\mathrm{a}}$ semana de idade.

Tabela 4. Maturidade sexual em dias na interação entre linhagens e debicagem na cria na $1 .^{a}$ semana de idade ${ }^{(1)}$.

\begin{tabular}{lccc}
\hline Tratamento & \multicolumn{2}{c}{ Debicagem na cria } & \multirow{2}{*}{ Média } \\
\cline { 2 - 3 } & Infravermelha & Lâmina quente & \\
\hline Linhagens & & & \\
Lohmann LSL & $135 \mathrm{Bb}$ & $137 \mathrm{Aa}$ & 136 \\
Hy-line W-36 & $137 \mathrm{Aa}$ & $136 \mathrm{Aa}$ & 136 \\
Lohmann Brown & $132 \mathrm{Ca}$ & $132 \mathrm{Ba}$ & 132 \\
\hline Média & 135 & 135 & \\
\hline${ }^{(1)}$ Médias seguidas por letras iguais, maiúsculas nas colunas e minúsculas \\
nas linhas, não diferem pelo teste de Tukey, a 5\% de probabilidade.
\end{tabular}

Tabela 5. Características de qualidade de casca dos ovos de três linhagens de poedeiras comerciais, submetidas a diferentes protocolos de debicagem na cria na $1 .^{\mathrm{a}}$ semana de idade e na recria na $10 .{ }^{a}$ semana de idade ${ }^{(1)}$.

\begin{tabular}{lccccc}
\hline Tratamento & $\begin{array}{c}\text { Número } \\
\text { de aves }\end{array}$ & $\begin{array}{c}\mathrm{GE} \\
\left(\mathrm{g} \mathrm{cm}^{-3}\right)\end{array}$ & $\begin{array}{c}\mathrm{RQ} \\
\left(\mathrm{g} \mathrm{cm}^{-2}\right)\end{array}$ & $\begin{array}{c}\mathrm{EC} \\
(\mathrm{mm})\end{array}$ & $\begin{array}{c}\text { Casca } \\
(\%)\end{array}$ \\
\hline Linhagens & & & & & \\
$\quad$ Lohmann LSL & 240 & $1,087 \mathrm{~A}$ & $3.880 \mathrm{~A}$ & $0,39 \mathrm{~A}$ & $9,39 \mathrm{~A}$ \\
Hy-line W-36 & 240 & $1,093 \mathrm{~A}$ & $3.884 \mathrm{~A}$ & $0,39 \mathrm{~A}$ & $9,42 \mathrm{~A}$ \\
Lohmann Brown & 192 & $1,092 \mathrm{~A}$ & $3.843 \mathrm{~A}$ & $30,80 \mathrm{~A}$ & $9,34 \mathrm{~A}$ \\
\hline Debicagem na cria & & & & & \\
$\quad$ Infravermelho & 336 & $1,088 \mathrm{~A}$ & $3.871 \mathrm{~A}$ & $0,39 \mathrm{~A}$ & $9,39 \mathrm{~A}$ \\
Lâmina quente & 336 & $1,093 \mathrm{~A}$ & $3.866 \mathrm{~A}$ & $0,39 \mathrm{~A}$ & $9,37 \mathrm{~A}$ \\
\hline Debicagem na recria & & & & & \\
$\quad$ Com & 336 & $1,091 \mathrm{~A}$ & $3.899 \mathrm{~A}$ & $0,39 \mathrm{~A}$ & $9,38 \mathrm{~A}$ \\
Sem & 336 & $1,090 \mathrm{~A}$ & $3.839 \mathrm{~A}$ & $0,39 \mathrm{~A}$ & $9,39 \mathrm{~A}$ \\
\hline Coeficiente variação (\%) & & 1,25 & 9,07 & 3,87 & 3,82 \\
\hline Linhagens (L) & & 0,24 & 0,91 & 0,28 & 0,74 \\
Debicagem na cria (D) & & 0,18 & 0,96 & 0,82 & 0,80 \\
Debicagem na recria (R) & & 0,64 & 0,49 & 0,70 & 0,91 \\
L x D & & 0,21 & 0,88 & 0,42 & 0,98 \\
L x R & & 0,13 & 0,87 & 0,50 & 0,51 \\
D x R & & 0,97 & 0,49 & 0,94 & 0,42 \\
Lx D x R & & 0,87 & 0,45 & 0,74 & 0,46 \\
\hline
\end{tabular}

${ }^{(1)}$ Médias seguidas por letras iguais, nas colunas, não diferem pelo teste de Tukey, a $5 \%$ de probabilidade. GE, gravidade específica; RQ, resistência à quebra; e EC, espessura de casca.

\section{Conclusões}

1. A debicagem por radiação infravermelha, na primeira semana de vida, é uma alternativa viável à debicagem por lâmina quente, para as três linhagens de poedeiras, pois o desempenho produtivo e a qualidade dos ovos não são alterados.

2. A ausência da segunda debicagem, na décima semana de vida, não leva ao canibalismo e não influencia nos índices de produção, para as três linhagens.

\section{Agradecimentos}

À Fundação de Amparo à Pesquisa do Estado de São Paulo (Fapesp, processo 2013/07312-8), pelo auxílio financeiro; e à Lohmann do Brasil, pelo apoio técnico.

\section{Referências}

ANGEVAARE, M.J.; PRINS, S.; STAAY, F.J. van der; NORDQUIST, R.E. The effect of maternal care and infrared beak trimming on development, performance and behavior of silver nick hens. Applied Animal Behaviour Science, v.140, p.70-84, 2012. DOI: 10.1016/j.applanim.2012.05.004. 
CARD, L. E.; NESHEIM, M. C. Producción Avícola. Zaragoza: Acribia, 1968. 392p.

CARRUTHERS, C.; GABRUSH, T.; SCHWEAN-LARDNER, K.; KNEZACEK, T.D.; CLASSEN, H.L.; BENNETT, C. On-farm survey of beak characteristics in white leghorns as a result of hot blade trimming or infrared beak treatment. Journal of Applied Poultry Research, v.21, p.645-650, 2012. DOI: 10.3382/ japr.2011-00433.

CUNNINGHAM, D.L.; MAULDIN, J.M. Cage housing, beak trimming, and induced moulting of layers: a review of welfare and production issues. Journal of Applied Poultry Research, v.5, p.63-69, 1996. DOI: 10.1093/japr/5.1.63.

DENNIS, R.L.; CHENG, H.W. A comparison of infrared and hot blade beak trimming in laying hens. International Journal of Poultry Science, v.9, p.716-719, 2010. DOI: 10.3923/ ijps.2010.716.719.

DENNIS, R.L.; FAHEY, A.G.; CHENG, H.W. Infrared beak treatment method compared with conventional hot-blade trimming in laying hens. Poultry Science, v.88, p.38-43, 2009. DOI: 10.3382/ps.2008-00227.

FAHEY, A.G.; MARCHANT-FORDE, R.M.; CHENG, H.W. Relationship between body weight and beak characteristics in one-day-old white leghorn chicks: its implications for beak trimming. Poultry Science, v.86, p.1312-1315, 2007. DOI: $10.1093 / \mathrm{ps} / 86.7 .1312$.

FOURNIER, J.; SCHWEAN-LARDNER, K.; KNEZACEK, T.D.; GOMIS, S.; CLASSEN, H.L. The effect of toe trimming on behavior, mobility, toe length and other indicators of welfare in tom turkeys. Poultry Science, v.94, p.1446-1453, 2015. DOI: 10.3382/ ps/pev112.

GENTLE, M.J. Pain issues in poultry. Applied Animal Behaviour Science, v.135, p.252-258, 2011. DOI: 10.1016/j. applanim.2011.10.023.
GLATZ, P. C. The effect of beak length and condition on food intake and feeding behavior of hens. International Journal of Poultry Science, v.2, p.53-57, 2003. DOI: 10.3923/ijps.2003.53.57.

GUESDON, V.; AHMED, A.M.H.; MALLET, S.; FAURE, J.M.; NYS, Y. Effect of beak trimming and cage design on laying hens performance and egg quality. British Poultry Science, v.47, p.1-12, 2006. DOI: 10.1080/00071660500468124.

JANCZAK, A.M.; RIBER, A.B. Review of rearing-related factors affecting the welfare of laying hens. Poultry Science, v.94, p.1454-1469, 2015. DOI: 10.3382/ps/pev123.

LAGANÁ, C.; PIZZOLANTE, C.C.; TOGASHI, C.K.; KAKIMOTO, S.K.; SALDANHA, E.S.P.B.; ÁlVARES, V. Influência de métodos de debicagem e do tipo de bebedouro no desempenho e na qualidade dos ovos de codornas japonesas. Revista Brasileira de Zootecnia, v.40, p.1217-1221, 2011. DOI: 10.1590/S1516-3598201100060000.

LEE, H.Y.; CRAIG, J.V. Beak trimming effects on the behavior and weight gain of floor-reared, egg strain pullets from three genetic stocks during the rearing period. Poultry Science, v.69, p.568-575, 1990. DOI: $10.3382 /$ ps.0690568.

MARCHANT-FORDE, R.M.; CHENG, H.W. Different effects of infrared and one-half hot blade beak trimming on beak topography and growth. Poultry Science, v.89, p.2559-2564, 2010. DOI: 10.3382/ps.2010-00890.

MERTENS, K.; LÖFFEL, J.; DE BAERE, K.; ZOONS, J.; DE BAERDEMAEKER, J.; DECUYPERE, E.; DE KETELAERE, B. Layers in aviary system: effects of beak trimming and alternative feed formulation on technical results and egg quality. Journal of Applied Poultry Research, v.18, p.90-102, 2009. DOI: 10.3382/ japr.2008-00025.

MORENG, R.E.; AVENS, J.S. Ciência e produção de aves. São Paulo: Roca, 1990, 380p.

Recebido em 18 de fevereiro de 2016 e aprovado em 4 de maio de 2016 